\section{U.S. Congress to consider future of Federal Helium Reserve}

www.blm.gov
I $n$ the coming months, the U.S. Senate may reexamine a 1996 Congressional decision to sell off the crude helium in the Federal Helium Reserve. Over the last 15 years the demand for helium has increased beyond expectations as helium has become increasingly fundamental to U.S. defense, health care, manufacturing, and research. Continuing to sell off the Federal Helium Reserve in accordance with the 1996 policy could lead to a number of negative consequences, such as an unstable domestic and global helium supply and significant price increases for helium users.

These consequences would be felt by many in the materials research community. "In materials research, any time when low temperatures or high magnetic fields are required, liquid helium is also required," said Robert Richardson, a 1996 Nobel laureate and low-temperature physicist at Cornell University. In addition, helium is essential for joining processes, surface-area measurement techniques like Brunauer-EmmettTeller (BET), pycnometry, and plasma processing of materials.

In early 2011, a report released jointly by the American Physical Society and the Materials Research Society made recommendations for securing supplies of the raw materials required for the emerging sustainable energy economy. Their report, Energy Critical Elements, advised against stockpiling elements because such reserves can discourage innovation, with the exception of helium. The physical properties of helium are so uniquely suited to cryogenic applications, manufacturing, and nuclearreactor designs that an unstable supply could be detrimental for U.S. research.

"The Committee does not recommend that the federal government es- tablish non-defense-related economic stockpiles of ECEs with the exception of one element: helium," reads the report. "The Committee concurs with and reiterates the APS Helium Statement of 1995: '[M] easures [should] be adopted that will both conserve and enhance the nation's helium reserves. Failure to do so would not only be wasteful, but would also be economically and technologically shortsighted."”

These conclusions are consistent with the recommendations of a 2010 report by the National Research Council (NRC), Selling the Nation's Helium Reserve. This report was requested by the U.S. Bureau of Land Management (BLM), who manages the reserve, to assess the impact of the current legislation on U.S. helium users. The report concluded that efforts to comply with the existing law, outlined in the 1996 Helium Privatization Act, have had and will continue to have negative impacts on U.S. helium users.

"If this path continues to be followed, within the next 10 to 15 years the United States will become a net importer of helium whose principal foreign sources of helium will be in the Middle East and Russia," said the report.

Congress established a federal helium program in 1925 to guarantee a stable helium supply for defense, research, and medical purposes. The United States began stockpiling crude helium - a gas that is more than $50 \%$ helium but may contain small amounts of methane, neon, hydrogen, and nitrogen - in earnest during the Cold War to serve aerospace and defense applications. Congressional amendments to the Helium Act in 1960 enabled the Secretary of the Interior to borrow money from the U.S. Treasury to buy helium, and gave natural gas producers incentives to strip helium and sell it to the U.S. government. This crude helium was stored in an underground facility just outside of Amarillo, Texas, and distributed to helium refiners through a federal pipeline.

By the mid-1990s, the U.S. stockpile consisted of one billion standard cubic meters ( $\mathrm{scm}$ ) of crude helium, estimated then to be more than enough to meet ongoing U.S. needs, incurred at a cost of $\$ 1.4$ billion. The overall helium supply was becoming more stable, with a growing private helium industry and increasing private demand. In response to these changes and motivated to re-

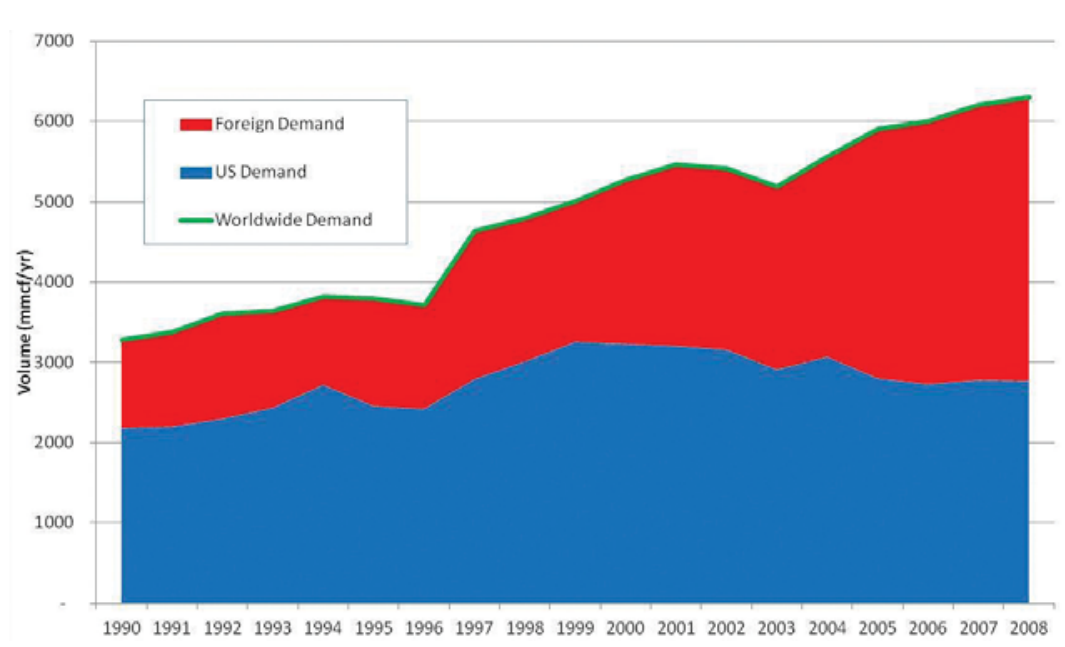

Consumption of refined helium in the United States, in other countries, and worldwide. By Cryogas International 
cover the $\$ 1.4$ billion, Congress passed the Helium Privatization Act in 1996. The Act called for the U.S. government to sell off any helium in excess of about 17 million scm on a straight line basis between January 1, 2005 and January 1, 2015. The selling began in 2005 after a NRC study reported that doing so would not have a substantial impact on helium users, barring any large unforeseen changes.

However, the non-U.S. demand for helium has increased significantly over the last 15 years, due to new industrial applications in areas like semiconductors and optical-fiber fabrication facilities. New helium-producing facilities have been built outside of the United States, but U.S. Federal Helium Reserve sales still account for half of U.S. helium demand and nearly one-third of global demand.

One of the main concerns that may drive Congressional action is that the price of crude helium has long been tied to a minimum price outlined in the 1996 Act that was set so as to recover the $\$ 1.4$ billion. Since it has not been tied to the market, the selling price of helium has not reflected its limited supply. "It is shameful how we squandered the helium we once held in reserve," said Richardson of the low cost at which much of the helium reserve was sold. Tying the price of helium to the minimum outlined in the 1996 Act enabled the BLM to sell much of the reserve, but caused rapid variations in the price and availability of open-market helium that were difficult for federally funded individual and small-scale researchers to ac- commodate. After the 2010 NRC report, BLM changed its pricing methodology to better reflect the market demand, but many think Congress needs to take further action.

Senators like Jeff Bingaman of New Mexico, chair of the Senate Committee on Energy and Natural Resources, would like to recover the U.S. investment in the reserve, but to do so in a way that ensures federal users like the Departments of Energy and Defense long-term access to crude helium, protects the nonrenewable nature of helium through a new pricing system tied to the market, and stimulates the development of private sources of helium.

Kendra Redmond

\section{Reactor Institute Delft to receive funding} www.rid.tudelft.nl

T he Reactor Institute Delft, home to Delft University of Technology's nuclear research reactor, will receive financial support from the state government to implement a program called the Optimized Yield-for Science, Technology, and Education - of Radiation, or OYSTER. Together with the funds that TU Delft and commercial parties are raising, this financial injection will give the institute the boost it needs to be able to maintain its position as the center of scientific expertise in nuclear and radiation research and education. The extra funds mean that the nuclear reactor can be fitted with a Cold Source. New, innovative research instruments will also be developed. These are essential for the development of materials for sustainable energy technology and for research into the detection and treatment of cancer, among other things.

The Cold Source - a device that can slow down the speed of neutrons-enables the neutrons to be more accurately guided for applications such as materials research. Director of the Reactor Institute Delft and TU Delft dean Tim van der Hagen said, "The slower neutrons are. . . much better at detecting abnormalities in materials, which means, for example, that the efficiency of solar panels and the capacity, charge rate, and safety of batteries can be drastically improved."

The Reactor Institute Delft is the Dutch center for multidisciplinary scientific research and education in reactor physics, neutron and positron radiation, radiation detection, and radiochemistry. A large part of the research focuses on medical applications, such as the production of medical isotopes and the diagnosis and treatment of cancer. In addition, new materials are being developed for sustainable energy such as solar cells and batteries, and work is being carried out to develop the nuclear reactors of the future.

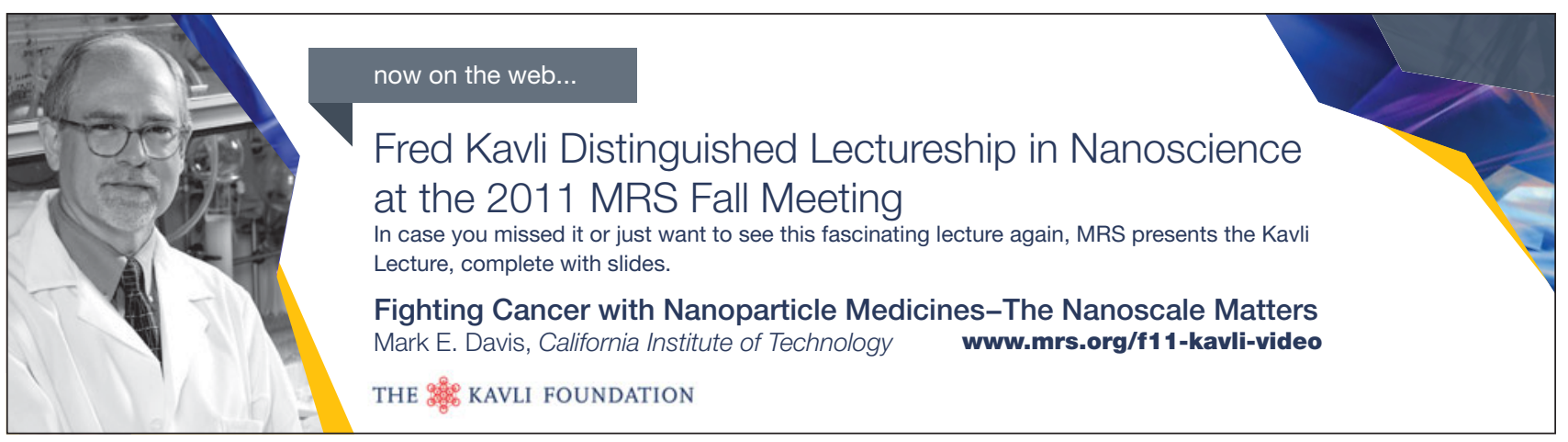

